\title{
Familial Cholestasis with Gallstone, Ataxia and Visual Disturbance
}

\author{
Yusaku Tazawa and Tasuke Konno \\ Department of Pediatrics, Tohoku University School of \\ Medicine, Sendai 980
}

\begin{abstract}
Tazawa, Y. and Konno, T. Familial Cholestasis with Gallstone, Ataxia and Visual Disturbance. Tohoku J. exp. Med., 1982, 137 (2), 137-144 - Two siblings with progressive intrahepatic cholestasis were reported. The brother died at 4 years of age because of hepatic failure followed by persistent obstructive jaundice starting at 4 months of age. The sister had unique clinical features, including recurrent obstructive jaundice since early infancy, radiopaque gallstone and neurological abnormalities which were cerebellar ataxia, bilateral ptosis, hyporeffexia and visual disturbance involving retinal degeneration and optic atrophy. She had a coarse facial appearance, camptodactyly and sclerotic skin with many scratch marks. Persistent high levels of serum bile acids were found while the patient was icteric and even anicteric, though serum cholesterol levels were approximately within normal limits. The serum lipoprotein-X was negative whenever examined. Cholestyramine treatment gave incomplete relief from pruritis but resulted in no improvement in her clinical course.

familial cholestasis; gallstone; cerebellar ataxia; visual disturbance
\end{abstract}

Many reports concerning familial intrahepatic cholestasis have been published. It seems to be caused by genetic defects, of which the pathogenesis has not been clarified in detail. Byler's disease is a familial fatal or progressive intrahepatic cholestasis which was first described by Clayton et al. $(1965,1969)$ in Amish families. Since then similar cases of familial intrahepatic cholestasis have been reported, but few cases had neurological abnormalities including mental retardation such as in the cases described by Juberg et al. (1966) and Hirooks and Ohno (1968). Recently Schubert et al. (1976) reported a unique case of congenital cholestasis, radiopaque gallstone and neurological abnormalities such as cerebellar ataxia. In this report we describe siblings with progressive intrahepatic cholestasis. One sibling also had a radiopaque gallstone, neurological disorders and visual disturbance associated with progressive intrahepatic cholestasis.

\section{Case Report}

Case 1. K.S., a body weighing $3,200 \mathrm{~g}$, born on November 22, 1962 to parents who were first cousins. He had jaundice first noticed at 4 months of age as evidenced by a gray-colored stool and dark urine, and was admitted to our ward at

Received for publication, August 8, 1981. 
8 months of age. On admission marked hepatomegaly was noticed. Laboratory data were as follows: Total bilirubin was $12.6 \mathrm{mg} / 100 \mathrm{ml}$, direct bilirubin $6.7 \mathrm{mg}$ / $100 \mathrm{ml}$, serum glutamic oxalacetic transaminase (GOT) 459 Karman units (KU), glutamic pyruvic transaminase (GPT) $268 \mathrm{KU}$, alakaline phosphatase 0.7 BesseyLowry units, thymol turbidity test 0.8 Kunkel units, serum cholesterol $208 \mathrm{mg} /$ $100 \mathrm{ml}$, serum total protein $7.6 \mathrm{~g} / 100 \mathrm{ml}$ (albumin $61.0 \%$, $\alpha$-globulin 9.3\%, $\beta$ globulin $7.4 \%, \gamma$-globulin $22.3 \%$ ), and a negative serologic test for syphylis. Liver biopsy showed findings of giant cell hepatitis with marked cholestasis. Radiological examination showed prominent rickets, which were improved with a supplement of vitamin $D_{3}$. Jaundice persisted, and his condition deteriorated by complications of infectious diseases such as acute bronchitis and pyelitis. His death at 4 years of age was due to hepatic decompensation. Autopsy showed biliary cirrhosis with patent extrahepatic bile ducts.

Case 2. N.S., a girl weighing $3,290 \mathrm{~g}$, was a sister of the above. She was admitted to our ward because of persistent jaundice first noticed at 5 days of life. On admission, in addition to jaundice, the enlarged liver was palpable $5 \mathrm{~cm}$ below the right costal margin. The laboratory data on admission were as follows: Total bilirubin was $11.0 \mathrm{mg} / 100 \mathrm{ml}$, direct bilirubin $8.0 \mathrm{mg} / 100 \mathrm{ml}$, GOT $460 \mathrm{KU}$, GPT $220 \mathrm{KU}$, alkaline phosphatase $27.5 \mathrm{King}$-Armstrong units, serum total cholesterol $324 \mathrm{mg} / 100 \mathrm{ml}$, phospholipid $322 \mathrm{mg} / 100 \mathrm{ml}$, serum total protein $6.6 \mathrm{~g} / 100 \mathrm{ml}$ (albumin $64.2 \%, \alpha_{1}$-globulin $6.2 \%, \alpha_{2}$-globulin $8.0 \%, \beta$-globulin $13.6 \%, \gamma$-globulin $8.0 \%$ ). X-ray findings showed evidence of rickets. The liver biopsy at 2 months of age showed findings of giant cell haptitis with marked cholestasis (Fig. 1). Jaundice gradually decreased, and at the age of 4 months serum total bilirubin was

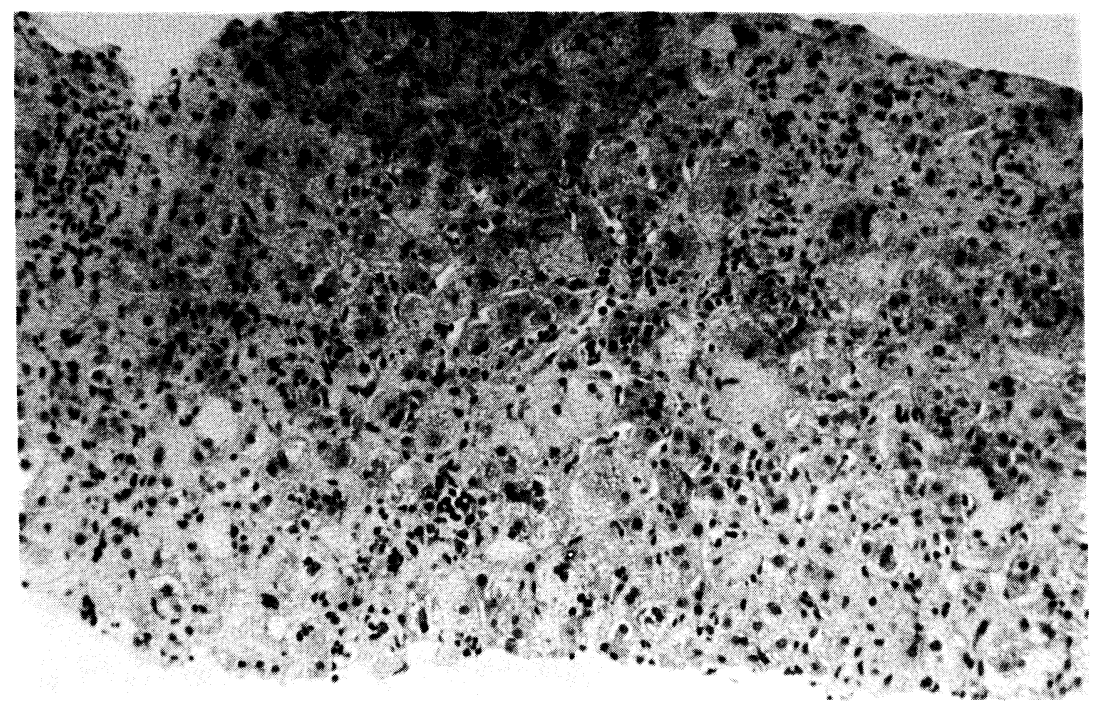

Fig. 1. Liver biopsy of Patient N.S. at 2 months of age. Giant cell transformation and mild round cell infiltration are noticed. Hematoxylin eosin stain $(\times 100)$. 
$3.6 \mathrm{mg} / 100 \mathrm{ml}$. During the subsequent follow-up period jaundice completely disappeared, while mildly increased levels of serum transaminases remained and hepatomegaly persisted. Jaundice recurred several times up to the second hospitalization at three years of age, at which time she had severe colic pain in the right costal margin as well as jaundice and a fever. The $\mathrm{x}$-ray study disclosed a pea sized radiopaque shadow under the liver bed. Under a diagnosis of gallstone with cholecystitis she underwent surgical treatment. An analysis of gallstone was not carried out. The cholangiography performed at the time of surgery revealed no obstructive lesions in the extrahepatic biliary tract. Biopsy findings of the liver showed marked cholestasis with bile pigments in hepatic cells and bile plugs in the canaliculi, and moderate mononuclear cell infiltration and slight fibrosis in the portal triad with little cell necrosis. After surgery episodes of jaundice developed once or twice yearly (Fig. 2), and pruritis persisted associated with growth retardation. Awkwardness in walking and running was noticed around 3 years of age. Gait disturbance which became worse after the patient suffered from measles at 9 years of age increased every slowly. It turned out to be due to cerebellar ataxia. The antibody response to the measle virus was normal. She complained of visual disturbance at the age of 10 years when bilateral ptosis was noticed. Ophthalmological examination revealed optic atrophy, degeneration of the maculae and retinae (Fig. 3), and contraction of visual field. Retinal lesions had been known to exist since infancy. Intelligence seemed to be normal up to preschool age, but thereafter mental retardation to a mild degree was noticed. Serial electroencephalograms showed findings within normal limits until 8 years of age, but the last record taken at the age of 12 years of age showed abnormal patterns as evidenced by irregular basal waves. Computed tomography of the brain revealed slight atrophy of the cerebellum but no abnormalities of the cerebrum or the ventricles. She had unique features including a coarse facial appearance (Fig. 4), camptodactyly (Fig. 5) and sclerotic skin with many scratch marks which became prominent with age.

Recurrent episodes of obstructive jaundice developed once or twice yearly. Pruritis remained even when the patient was anicteric. Serum bile acid levels

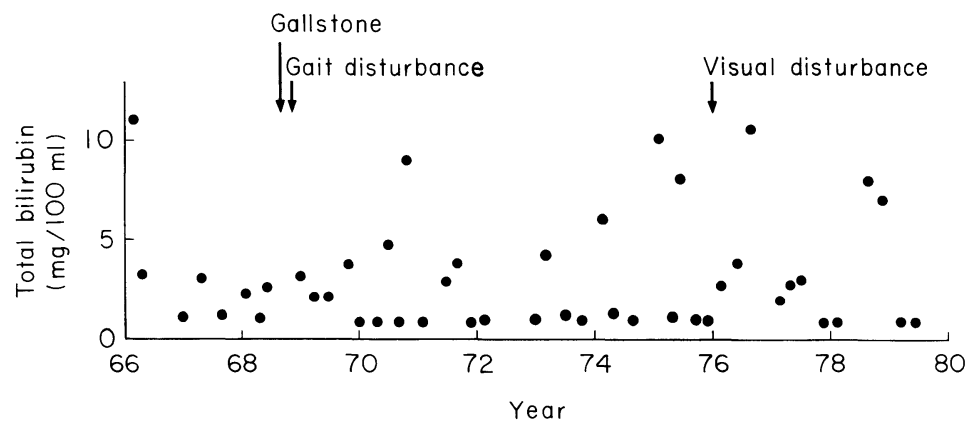

Fig. 2. Clinical course and serum total bilirubin levels of Patient N.S. during the 14 year period of observation. 


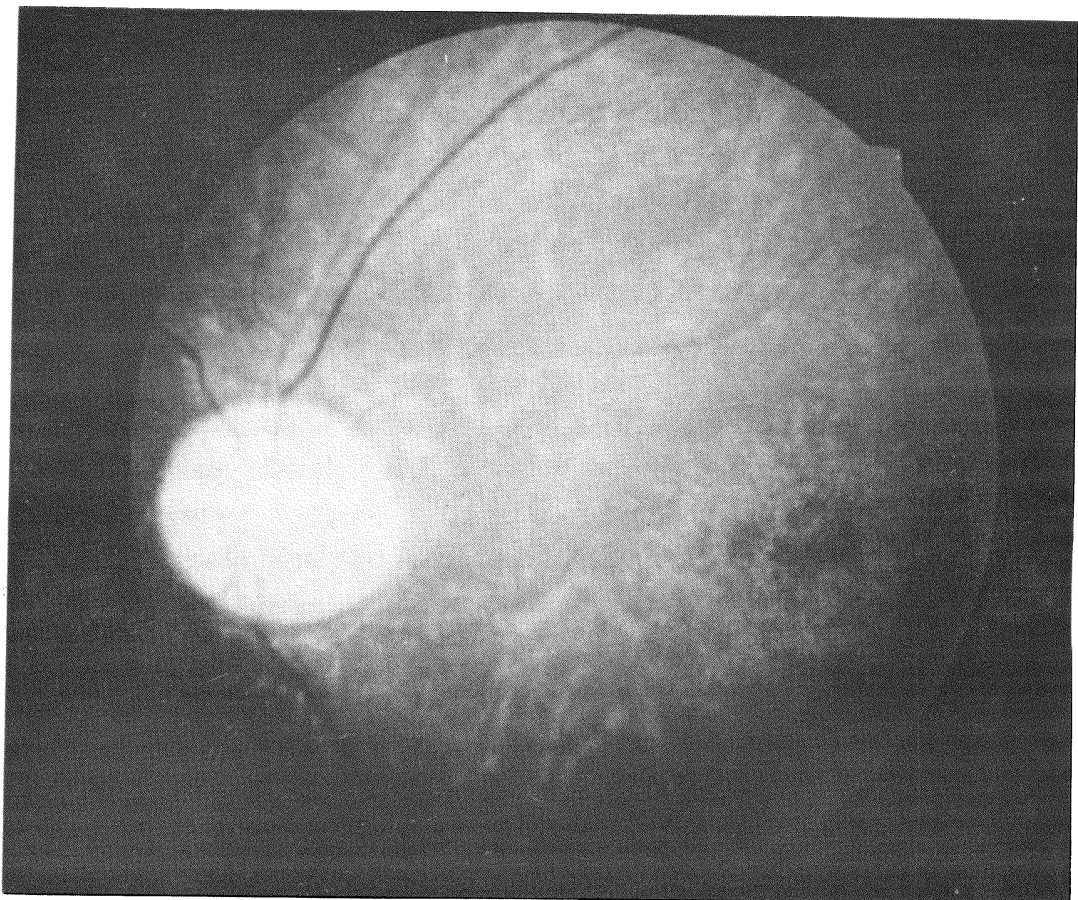

Fig. 3. Funduscopy of Patient N.S. Note degeneration of the macula and retina.

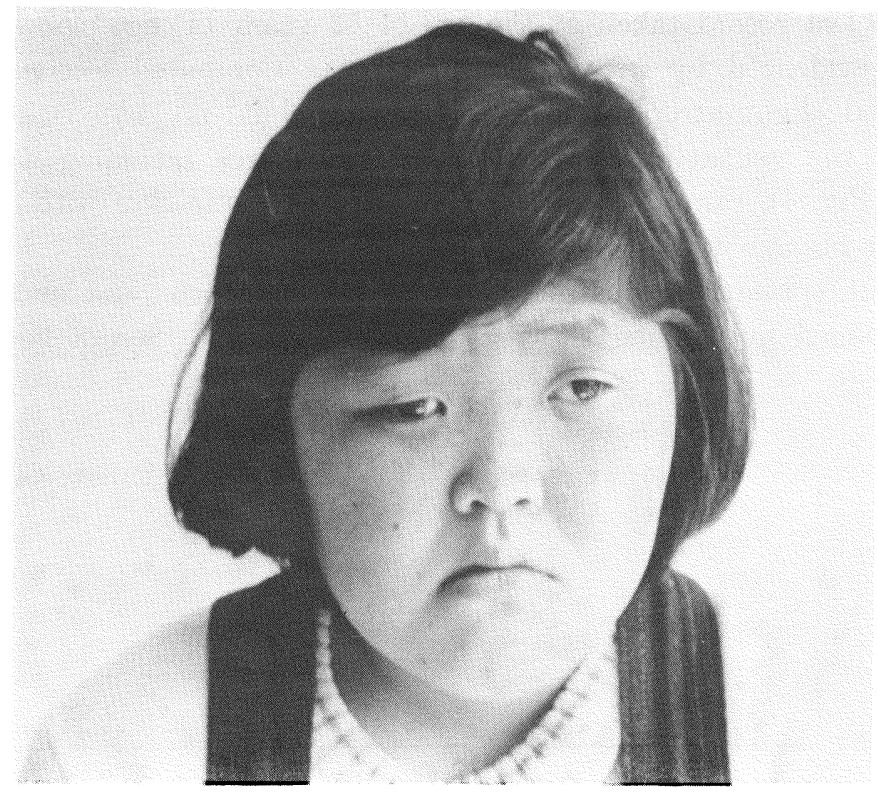

Fig. 4. Patient N.S. Coarse facial appearance and bilateral ptosis are noticed. 


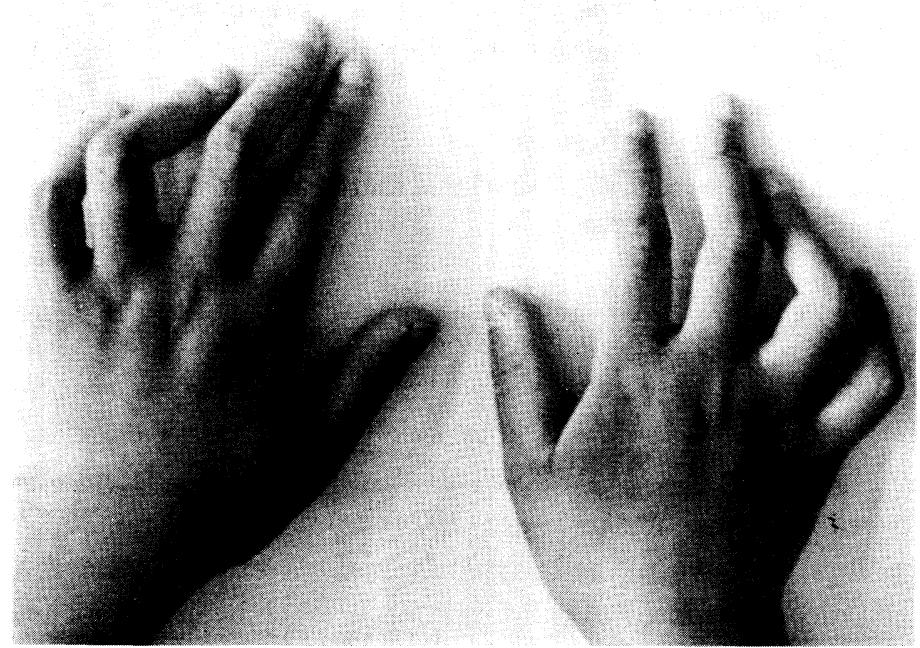

Fig. 5. Hands of Patient N.S. Camptodactyly is apparent, especially in the third to fifth fingers.

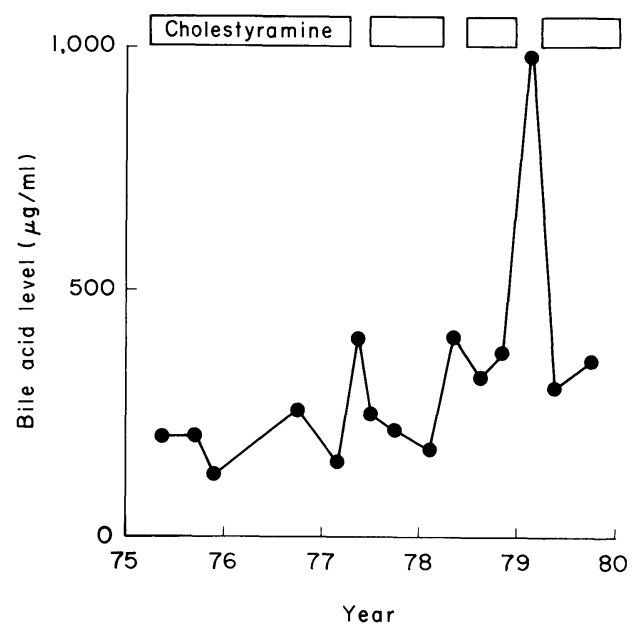

Fig. 6. Serum bile acid levels of Patient N.S. in relation to cholestyramine therapy.

ranged from 121 to $968 \mu \mathrm{g} / \mathrm{ml}$ (Fig. 6), which was analyzed by gas-liquid chromatography using a $0.2 \%$ Poly-I 110 column. The serum cholesterol ranged from 84 to $235 \mathrm{mg} / 100 \mathrm{ml}$, and phospholipid ranged from 108 to $219 \mathrm{mg} / 100 \mathrm{ml}$. No xanthoma was found. The serum lipoprotein-X was negative whenever examined. Other laboratory findings were as follows: Serum $\alpha_{1}$-antitrypsin was $423 \mathrm{mg} / 100 \mathrm{ml}$, ceruloplasmin $133 \mathrm{mg} / 100 \mathrm{ml}$, serum cholestanol $31.8 \mu \mathrm{g} / \mathrm{ml}$, and serum betalipoprotein $341 \mathrm{mg} / 100 \mathrm{ml}$. The serum vitamin $\mathrm{E}$ level was $0.07 \mathrm{mg} / 100 \mathrm{ml}$ (normal ranges, 0.75-1.40). Serum alkaline phosphatase was well controlled by the administration of vitamin $\mathrm{D}_{3}$. Leucine aminopeptidase and $\gamma$-glutamyl transpeptidase were within normal limits. Hepatitis B surface antigen was 
negative. She had ascites during the last icteric period, which was controlled by the administration of spironolactone and diuretics.

The administration of cholestyramine gave incomplete relief from prurits, but seemed to have no positive effect on her clinical course. Other agents such as prednisolone, antihistamics and phenobarbital had little effect on pruritis or jaundice.

\section{Descussion}

Various terms have been used in reporting familial occurrence of cholestatic jaundice: familial form of benign idiopathic recurrent cholestasis (Goldberg and Hendry 1967), familial intrahepatic cholestatic jaundice (Gray and Saunders 1966), fatal intrahepatic cholestasis (Linarelli et al. 1972), progressive familial intrahepatic cholestatic cirrhosis (Williams et al. 1972), progressive familial intrahepatic cholestasis (Ballow et al. 1973), and severe familal cholestasis (Odièvre et al. 1973). However, they do not represent uniform features clinically, biochemically and pathologically.

The unique features of our cases can be summarized as follows: 1) familial progressive intrahepatic cholestasis, 2) cholestatic jaundice in infancy (giant cell hepatitis), 3) recurrent episodes of obstructive jaundice, 4) unusually high levels of serum bile acids even while anicteric, 5) subnormal to normal levels of serum total cholesterol, 6) mildly increased levels of serum GOT and GPT, 8) external abnormalities including a coarse facial appearance, comptodactyly and sclerotic skin with many scratch marks, 9) neurological abnormalities including cerebellar ataxia, bilateral ptosis and hyporeflexia, 10) visual disturbance involving retinal degeneration and optic atrophy, and 11) radiopaque gallstone.

These findings, especially the neurological abnormalities, visual disturbance and radiopaque gallstone, are unusual in cases of familial intrahepatic cholestatic syndromes so far reported. A similar case was reported by Schubert et al. (1976). His patient had a radiopaque gallstone and neurological abnormalities such as cerebellar ataxia, bilateral ptosis and hyporeflexia. Association of mental retardation and familial intrahepatic cholestasis has been reported by Juberg et al. (1966) and Hirooka and Ohno (1958). Either our case or Schubert's case showed no signs of mental retardation during preschool age. Cerebellar ataxia was first apparent as gait disturbance and then became worse with time, complicated by visual disturbance due to retinal degeneration and optic atrophy. Cerebral involvement was also suggested by later abnormal electroencephalogram findings. A radiopaque gallstone was found in our case as well as in Schubert's. There was a case of familial intrahepatic cholestasis in which a gallstone was incidentally detected at laparotomy (Odièvre et al. 1973). In Schubert's case it was described to be a cholesterol gallstone, but in the present case chemical analysis of the gallstone was not done. In general, cholesterol gallstones are of radiolucent quality (Danzinger et al. 1972; Bell et al. 1972), and thus it may be suspected that an abnormal composition of bile contributes to the process resulting in a gallstone, which is different from the pathogenesis of cholesterol gallstones. 
The serum lipoprotein-X, well known to be a sensitive and specific marker of cholestasis (Seidel et al. 1973), was always negative when examined in the present case. Increased pressure in the biliary tract, important for the regurgitation of bile in the biliary tract, seems also to be important in the regurgitation of bile lipoprotein in systemic circulation and the production of lipoprotein-X (Ritland and Bergan 1975). Negative lipoprotein- $X$ may suggest that cholestasis is caused at the level of the hepatic cell, not by regurgitation of bile from the biliary system. The normal levels of serum cholesterol support this speculation.

Retinal degeneration and ataxia are found in abeta-lipoproteinemia (Salt et al. 1960) and familial hypobeta-lipoproteinemia (Kuo and Basset 1962). The serum cholesterol levels of our case were usually normal, although slight low in the later stage probably due to liver cirrhosis. The serum beta-lipoprotein level was shown to be within normal ranges.

Recently a progressive neurological syndrome in children with chronic liver disease has been documented by Rosenblum et al. (1981). The neurological syndrome is very similar to that of our case. In their report they discussed neurological disorders seen in patients with long-term cholestasis as being the result of chronic vitamin $\mathrm{E}$ malabsorption. In the present case the serum vitamin $\mathrm{E}$ value was extremely low. In the view of the report by Rosenblum et al. (1981) such a low serum level of vitamin $\mathrm{E}$ may play a role in the pathogenesis of neurological disorders.

\section{References}

1) Ballow, M., Margolis, C.Z., Schachtel, B. \& Hsia, Y.E. (1973) Progressive familial intrahepatic cholestasis. Pediatrics, 51, 998-1007.

2) Bell, G.D., Whitney, B. \& Dowling R.H. (1972) Gallstone dissolution in man using chenodexoycholic acid. Lancet, 2, 1213-1216.

3) Clayton, R.J., Iber F.L., Ruebner, B.H. \& McKusick, V.A. (1965) Byler's disease: Fatal familial intrahepatic cholestasis in an Amish Kindred. J. Pediat., 67, 10251028

4) Clayton, R.J., Washington D.C., Iber, F.L., Ruebner, B.H. \& McKusick, V.A. (1969) Byler's diseases: Fatal famlial intrahepatic cholestasis in an Amish Kindred. Amer. J. Dis. Child., 117, 112-124.

5) Danzinger R.G., Hofmann A.F., Schoenfield L.J. \& Thistle, J.L. (1972) Dissolution of cholesterol gallstones by chenodeoxycholic acid. New Eng. J. Med., 286, 1-8.

6) Goldberg, D.M. \& Hendry, E.B. (1967) Familial form of benign idiopathic recurrent cholestasis. Arch. intern. Med., 120, 556-564.

7) Gray, O.P. \& Saunders, R.A. (1966) Familial intrahepatic cholestatic jaundice in infancy. Arch. Dis. Child., 41, 320-328.

8) Hirooka, M. \& Ohno, T. (1968) A case of familial intrahepatic cholestasis. Tohoku J. $\exp$. Med., 94, 293-306.

9) Juberg, R.C., Holland-Moritz, R.M., Henley, K.S. \& Gonzalez, C.F. (1966) Familial intrahepatic cholestasis with mental and growth retardation. Pediatrics, 38, 819836.

10) Kuo, P. \& Basset, D.R. (1962) Blood and tissue lipids in a family with hypo-betalipoproteinemia. Circulation, 26, 660.

11) Linarelli, L.G., Williams, C.N. \& Phillips, M.J. (1972) Byler's disease: Fatal intrahepatic cholestasis. J. Pediat., 81, 484-492.

12) Odièvre, M., Gautier, M., Hadchouel, M. \& Alagille, D. (1973) Severe familial 
intrahepatic cholestasis. Arch. Dis. Child., 48, 806-812.

13) Ritland, S. \& Bergan, A. (1975) Plasma concentration of lipoprotein-X (LP-X) in experimental bile duct obstruction. Scand. J. Gastroent., 10, 17-24.

14) Rosenblum, J.L., Keating J.P., Prensky, A.L. \& Nelson, J.S. (1981) A progressive neurologic syndrome in children with chronic liver disease. New Engl. J. Med., 304, 503-508.

15) Salt, H.B., Wolff, O.H., Lloyd, J.K., Fosbrooke, A.S., Cameron, A.H. \& Hubble, D.V. (1960) On having no beta-lipoprotein: A syndrome comprising a-beta-lipoproteinemia, acanthocytosis, and steatorrhea. Lancet, 2, 325-329.

16) Schubert, W.K., Partin, J.S. \& Partin, J.C. (1976) Congenital cholestasis: Clinical and ultrastructural study. In: Liver Diseases in Infancy and Childhood, edited by S.R. Berenberg, Martinus Nijhoff Medical Division, Hauge, pp. 148-162.

17) Seidel, D., Gretz, H. \& Ruppert, C. (1973) Significance of the LP-X test in differential diagnosis of jaundice. Clin. Chem., 19, 86-91.

18) Williams, C.N., Kaye, R., Baker, L., Hurwitz, R. \& Senior, J.R. (1972) Progressive familial cholestatic cirrhosis and bile acid metabolism. J. Pediat., 81, 493-500. 